\title{
Why Indian E-Retailing Market is Still a Partly Success and a Partly Failure Story?
}

\section{Debasis Ghosh*}

Assistant Professor, Bengal College of Engineering and Technology, Durgapur-12, West Bengal University of Technology, West Bengal, India

\begin{abstract}
With the increase in number of household computers and fast spreading internet connections, especially broadband connections, India have been experiencing an exponential growth in number of internet users in last decade or so. Conversions with significant Compound Annual Growth Rate of those online users into online buyers resulted in a huge Indian ecommerce market including online retailing market. This paper is mainly focused to analyze why the status of Indian ecommerce and E-tailing market is not very rosy till date since inception, why E-tailing has not reached the desired goal which includes the financial gain achieved by Indian online retailers though there are huge growth observed regarding the Internet usage and more inclinations of online Indian users towards online shopping in recent times. The Study is then aimed at behavioral trend of Indian online consumers so far. This study investigates the positive and negative influencers or variables which have been driving Indian users to search and buy online or stops them to shop in the virtual world in Indian socio-cultural scenarios. Finally a set of constructive solutions would be found to encourage and attract larger number Indian online users to shop through internet and would be proved beneficial for Indian e-tailors implementations wise and for future researchers who will work on this topic as well.
\end{abstract}

Keywords: Challenges for online purchase; E-commerce; E-tailing; Online buying behavior; Online vendors

\section{Introduction}

World had experienced a complete change in the virtual world from the age of ARPANET to the current age of technically advanced, customized and much more user friendly online environment. Indians are also not lagging far behind they are now more computer literate, techsavvy, well informed and strongly socially connected. Per capita income of Indian working male and female is increasing day by day. Affluence has changed the online consumption pattern of Y (age between mid-20 Years and mid 30 Years) and X (age above 40 years) generations of India resulted in a culture of online consumerism. According to Hoffman et al. [1] marketing communication model which is now driven by hypermedia computer aided environment promoted Internet marketing greatly. Internet marketing can be defined as advertising, promoting and finally selling goods and services using internet. Email marketing, blogs, Pay per Click, affiliate marketing, banner advertisements are different forms of Internet marketing. Business is now changed from commerce to E-commerce and retailing to internet retailing. Ecommerce means marketing, purchasing, selling, distribution and servicing with the help of electronic media like internet and other networks aided by www, email, databases etc. with the goal of commercial transactions and facilities like many alternative options, anytime- anywhere shopping, attractive customized informative business portals, cheap and best deals, comparative analysis of attributes and prices of different available online products and services and many more. E-tailing is another name of online retailing, which mainly aims at e-shopping by online users. Singla et al. [2] explained e-shopping where consumers perform an exchange through a computer based interface while buyer's computer interact with digital retailer to buy any thing over internet. E-retailing is still at very early stage in India and still is an unorganized sector with the third party business model and without proper big brand based e-retail market. Though computer literacy in India had increased but only 100 million (indiatechonline. com) [3] households had Pcs or laptops. Widespread geographical areas and lack of proper physical infrastructure had been causing problems to Indian government to provide internet connections in all urban rural cities that caused only 66 million broadband connections, 19 million wired and 47 million through mobile (indiatechonline.com) [3] could be possible to spread over India. But with the increase in computer literacy and overcoming the mental blockage regarding technical know how to operate internet, India became the $3^{\text {rd }}$ largest country in the world regarding number of online users with the database of 213 million as of 2013 a year-on-year growth of $28 \%$, is expected to touch 243 million by June, 2014 though the penetration rate was only 19.19\% (IAMAI) [4]. Among them 200 million were active internet users, around 140 million represented urban India and 60 million online users' belonged to rural India as of December, 2013. More rural participations in future are expected with the aid of affordable smart phones, optic fiber infrastructure and future usage of local language content in Indian portals (IMRB and IAMAI) [4]. Indian online users gradually understood many benefits of e-retailing and got attracted towards many facilities offered by e-vendors. Online population had overcome different mental barriers as socio-cultural conservativeness, feel and touch consumer behavior, insecurity regarding exposing personal details like credit and debit card details over the internet etc. in Indian context and became much more practical, less sentimental and with much more information has been now accepting e-retailing model in a very fast way. With enough disposable income, fast lifestyles Indian online users had been executing impulse buying behavior which is essential for online shopping in last few years, in turn causing actual online shopping which increased revenue earned from Indian e-tail market in India which had a positive effect on country's economy, govt. revenues, urban and rural development, industrial growth and created

*Corresponding author: Debasis Ghosh, Assistant Professor, Bengal College Of Engineering and Technology, Durgapur -12, West Bengal University Of Technology, West Bengal, India, Tel: 08946027994; E-mail: debasisghosh32@gmail.com

Received May 22, 2014; Accepted August 04, 2014; Published August 11, 2014

Citation: Ghosh D (2014) Why Indian E-Retailing Market is Still a Partly Success and a Partly Failure Story? J Account Mark 3: 113. doi: 10.4172/2168-9601.1000113

Copyright: ( 2014 Ghosh D. This is an open-access article distributed under the terms of the Creative Commons Attribution License, which permits unrestricted use, distribution, and reproduction in any medium, provided the original author and source are credited. 
new employment opportunities. Online buying behavior of Indians had been quite different from traditional one and this behavior and purchase decision process had been influenced by many socio-culturaltechnical positive and negative aspects in Indian context. Indian social values and cultures had impacted Indian online shopping attitude hugely. According to Schiffman et al. [5] consumer behavior can be described as, "how they evaluate it after the purchase and the impact of such evaluations on future purchases and how they dispose it off".

\section{Literature Review}

In today's world business houses use online business as one of the major marketing tools to increase their revenues and capture lion share of the market in a quick and effective way. Indian ecommerce and E-tailing market is growing but with a slow pace as compared to other developed global online markets. It is important to know the positive and negative influencing factors behind Indian online actual behaviors. With regard to the above a review of some relevant literature is as follows:

Anderson [6] found how Indian E-Commerce market is growing overcoming the payment challenges. Amar [7] discussed about different challenges for Indian E-Commerce market various reasons behind the online purchases and effect of those factors on Indian males and females were studied by Srikanth et al. [8]. A blog was written in 2011 on the challenges for Indian E- commerce market [9]. Lina et al. [10] discussed on online shopping acceptance model. Dubey [11] said Ecommerce market was aiming at a very high growth. E-marketer [12] research explored different online activities which majorly included searching and purchasing online in India. Detailed study was being carried on buying behaviors of Indian online shoppers by Ankur [13]. Gupta et al. analyzes different new marketing approaches to influence customer behavior [14]. iXigo.com [15] survey revealed Indian online travel buying behavior. Dholakia [16] analyzed the growth rate of online shopping in India. How Indian ecommerce market was growing overcoming the payment problems was explained by Suw [17]. Kumar et al. threw light on buying behavior of Indian online consumers [18]. Sandeep [19] came up with the negative factors for E-tailing market in India. Singhi et al. explored consumers' purchasing decisions regarding retailing [20]. Different current statistics regarding online shopping, ecommerce market was found from slideshare.com [21]. Chitraparna [22] studied scope of online market in India in 2012 with the view of consumer behavior. Importance of opinion leadership and maven and their impact on the purchasing decision process of Indian online shoppers was emphasized by Raj et al. [23]. Varun et al. [24] discovered the impacts of social media specially Facebook on online users mind before actual online shopping. Different driving forces for E-tailing were explored by Satish et al. [25]. Tripathy came up with different challenges for Indian ecommerce sites [26]. Richa [27] explained different demographic variables those had impact on Indian online buying behavior. Nisha et al. [28] discussed about future of Indian ecommerce market regarding variables which influenced Indian online consumers' purchase decisions and challenges for Indian ecommerce market. Akansha et al. [29] said about different factors which affected Indian consumers' buying decision processes. Future of e-retailing in India was predicted by Sabyasachi et al. [30]. Zhou et al. discussed on online shopping acceptance model based consumers' factors [31]. Kumar et al. discussed on Internet mavens regarding online shopping [23]. Potturi et al. analyzed trends and forecasting regarding online shopping, ecommerce and internet marketing [32]. Wang et al. [33] considered impact of social interactivity had great impact on online shopping. Mukesh [34] threw light on status of ecommerce market in India. Saeed et al. [35] explored different online shopping attributes already investigated in some previous studies. Singla et al [2] found reasons what stopped Indians to buy online and analyzed the potential of online shopping in India. Wigder et al. discovered trends in online marketing [36]. Smita et al. [37] explained the effect of Web 2.0 technology on Indian online consumers. Shahriar et al. [38] analyzed general consumer behavior. According to a blog written [9] challenges for Indian ecommerce market and solutions to overcome those problems, were analyzed. Zia et al. [36] let us know about the trend in Indian ecommerce market. Indianknowledge@wharton [39] research came out with Indian E-tailing market's current scenarios and challenges it had been facing. Preeti [40] gave an overview of Indian ecommerce market and explained different E-tailing market. Dr. Deepa [41] discussed on how more people interested to buy online with the increase in disposable income and convenience provided by online shopping platform.

Erik [42] suggested online retailers to rebuild their strategies regarding the differences between physical and online retailing based on modern web technologies. Internetlivestas.com [3] gave current information on online scenario. Indiatechonline.com [2] threw light on current data on Indian internet usage and online market.

\section{Objectives of the Study}

Main objective and research motivation of the study is, why Indian E-tailing market has not reached the desired goal in terms of market share and financial gains, this is the main problem area of this research paper and then to know the behavioral trend of Indian consumers towards internet buying which throws the light on the issue why Indian online market has not got the desired success. Other specific objectives are given below:

\section{- To analyze the current status of Indian E-tailing market.}

- To study positive influencing factors responsible for online shopping and negative factors which stop Indian users to buy online in India.

- To find out the ways to increase the number of new online consumers, retaining the existing online customers and come up with relevant solutions to overcome the challenges for Indian online shopping.

All the above mentioned objectives are based on secondary data with respect to Indian online retailing and shopping investigated in previous researches, studies, papers and journals.

\section{Research Methodology}

Secondary data sources were used for this research purpose. Detailed studies and analysis of available maximum secondary data on the study topic were being carried. Online and offline previous research papers, articles, literatures, journals, reviews on the research objective were the main sources for secondary data and the period of data is between 2007-2014. And the details of the secondary sources are being mentioned in literature review and references section.

\section{Findings from the study}

Behavioral pattern of Indian online shoppers: Since 1996, ecommerce and e-tail model had been gaining popularities among active Indian online users and they started giving priorities to online shopping over traditional physical buying. Increase in computer literacy made Indian online mass efficient enough to search for best available options in virtual world. With the detailed knowledge about brands and 
their offerings they exhibited complex online buying behavior. Online vendors and brands seeing the huge scope of Indian E-tailing market started giving weight on the analysis of Indian online shoppers' psyche and buying decision making processes. Indian consumers exhibited two mail attributes - value and family orientation. Middle and upper middle income groups in India represented major chunk of shopping mass. They were actually interested in value for money, mainly very price sensitive and believed in quantity rather than quality of any product or service. Their purchase decision processes always being driven by families and friends. Loving and caring in nature Indians always accepted those online offerings which strongly communicated emotions. Acceptance of e-tail model of shopping started by rich and upper rich people of India, who loved to buy exclusive items of big brands and the same time conservative middle class Indians who looked for longevity of products and maximum usage at rate of minimum prices, refused to accept online shopping at first go. But gradually they understood the benefits of online model and started getting attracted to it and they started the new experiments with online travel related buying whether hotel booking, ticketing etc after many comparison searches consulting at least more than a site and they looked for cost, location and brand. Indian ecommerce market was worth Rs. 62,967 crores in 2013 with a growth of $33 \%$ against 2012 and about $71 \%$ of this was travel related IAMAI [3].

According to Indian consumer behavioral trends online shoppers liked to research and then finally went for shopping for following products: Travel, Consumer Electronics, Mobiles, Jewelries and Watches, Fashion Accessories, Books, Music Downloads, Software and hardware, Grocery Items, Baby Food and Products, Local Classifieds.

Coupon sites were on fire in last few years and attracted many new online consumers, $16.5 \%$ of the total online mass went for those sites in 2011 Nisha et al. [27].

Reviews and feedbacks in social networking sites like blogs, Facebook and Twitter, from existing online consumers about any offering impacted buying decision process of new but interested online users greatly. Opinion leaders called as mavens with their acceptance in the societies controlled the direction of communications and could mold online shoppers' intention in positive or negative ways. Rural online mass was still reluctant to adopt online shopping; only around $33 \%$ of rural online users went for online Shopping where around $70 \%$ urban users actually did online shopping (http://www.slideshare.net/ iibea/digital-statistics-2014-india). Indian youths specially the students exhibited most positive attitude towards online buying which counted for $91.43 \%$ of total online shoppers followed by service people marked at $5.71 \%$. People aged between 18 years to 40 years did the maximum online shopping in India so far.

$92 \%$ of young Indians agreed that official sites were good places to gather information about their offerings, $88 \%$ of them said they would love to the photos of the products of different available online brands on portals and 875 liked to read and trust already online consumers' review over some product or service on those portals or on social networking sites before going ahead to shop online.

Indian males took more interest than females, $61 \%$ males went for online shopping where females were lagging behind with 39\% (http:// www.slideshare.net/iibea/digital-statistics-2014-india). It had been observed that Indian women used not to like to buy online and felt less satisfied if they did so, because they would love to touch, feel, bargain and then buy. But participations by females specially the working ones in India had been increasing greatly which would be a very positive sign for future e-tail market. General characteristics of global online buyers - they were innovative, variety - seeking, price - non sensitive and less risk averse which were actually opposites of general Indian online buyers' psyche that's why only there were only 2.5 crores online shoppers out of 21.3 crores Indian internet users IAMAI [3].

\section{Growth story of internet, E-commerce as well as E-Retail market in India}

Healthy competitions among computer vendors and internet service providers brought down the prices and costs of computers and internet connections encouraged more Indians to become online users. High speed broadband usage had been experiencing a 20\% growth rate per month since inception, as of number of broadband connections were given across India touched 66 million mark (July, 2014). India had 213 million internet users in 2013 with a growth rate of $42 \%$ from 150 million in 2012 still it counted for only $8.33 \%$ share of world internet users (internetlivestats.com, 2014). Among 213 million users there were 200 million were active online users. $87 \%$ of them used internet for communication and $67 \%$ of the total Indian online population surfed for social networking. Number of rural online users was also increasing and touched 60 million marks by 2013. With cheap smart phones participations form rural mass would be expected much more in near future. India became the $3^{\text {rd }}$ largest country after China and USA with respect to number of internet users. As of 2013 out of 213 million Indian users $70 \%$ of them accessed internet through mobiles (IMRB and IAMAI) [3].

Still India was lagging far behind regarding household Pcs and laptops and internet penetration rate. Only 100 million Indian had own computers and 66 million household had internet connections representing as of November, 2013 (IAMAI) [3]. Geographical widespread, lack of proper infrastructure, cost, very less internet connections through India, conservativeness were some of the major factors behind low internet penetrations especially in rural areas. As of 2013 internet penetration rate was 19.19\%, Indian internet users number represented only $8.33 \%$ of world internet users where China counted $21.97 \%$ (2014). In 2013- 2014 internet penetration rate was $19.19 \%$ in India while rest of world's average penetration rate was above 40\% (internetlivestats.com, 2014), E-retailers realized this gap and huge market scope in Asia and India in near future. Indian e-tailing had experienced a steep average growth rate of around 25\% as of 2013 which broke the traditional beliefs that Indian consumers only like brick - mortar buying model and averse to online shopping (IMRB and IAMAI) [3]. IMRB International and IAMAI had given the following encouraging facts for Indian e-tail market: 25\% Indian registered user's accessed internet daily, $64 \%$ accessed during working days with their busy schedules and it increased up to $71 \%$ in weekends. Work audiences were the largest online users group with their disposable income and positive online shopping attitudes. It was observed that once Indians started online buying their behavior remained unchanged.

Since the launch of Indian ecommerce site - rediff.com, Indian e-commerce market had gone through many ups and downs and gradually gained quite a bit acceptance from Indian audiences. In 2009 Indian ecommerce market was worth $\$ 2.5$ billion which increased almost 4 times to touch $\$ 8.5$ billion mark in 2011 and went up to \$12billion in 2012 almost 6 times from 2009 in just 3 years with a annual growth of 70\% (Nisha and Sangeeta, 2012, resaerchmanuscripts.com/ isociety2012,7.pdf). Indian e-tail market was worth Rs.63 crores in 2013 and expected to touch $\$ 9$ billion in 2016 with the estimated CAGR of $61 \%$ (IAMAI) [3]. But the major problem for Indian e-tail market was 
it was still driven by $3^{\text {rd }}$ party market place model with a very few brand driven ecommerce project (en.wikipedia.org|wiki|E-comm_in_India). Advertisements of e-retailers like myntra.com, flipcart.com etc. in Indian TV prime slots indicated towards acceptance of online shopping model by Indian audiences. Flip Kart shipped 30000 orders per day and their revenue touched \$1billion as of December, 2013. (http:// www.vccircle.com/news/technology/2014/03/07/flipkart-says-it-hashit-annual-revenue-run-rate-1b-gmv, 2013), this result cemented the success story of Indian E-tail market (Source: Comscore). Snapdeal. com had been converted from discount site to online market place they were offering products of more than 3000 brands and shipping to 4000 Indian cities. According to cofounder of myntra.com, Mukesh Bansal they expected to touch Rs.800 crores in 2013 - 2014 and expected to touch Rs. 1500 crores mark by 2015 (http://www.thehindubusinessline. com/industry-and-economy/info-tech/myntracom-eyes-rs-800-crturnover-in-201314/article4763134.ece,http://articles.economictimes. indiatimes.com/2014-02-06/news/47090047_1_mukesh-bansalmyntra-ashutosh-lawania, 2014). Online grocery market was also gaining popularity very fast. Urban Indians had accepted mygrahak. com and basket.com, mygrahak.com would touch $\$ 179.1$ million by 2015, they already had 22000 registered Indian users and signup rates had been increasing around $25 \%$ per month. Urban India started relying on firstcry.com for baby products as well. Because of the FDI rule Big Global online vendors were unable to enter Indian e-market directly but with the partnerships with local online vendors they started selling in Indian market. Amazon partnered with Junglee.com and eBay did the acquisition of Bazee.com. Amazon got the government permission for setting up large warehouses across India to stock $3^{\text {rd }}$ party merchandise. EBay entered Indian market in 2004, currently had 3million registered Indian users and over 25000 sellers in India (forrester.com, 2012). Venture capitalists started to take interest in Indian online market and already had invested \$177million in 2011 and there were 34 deals underway worth \$282million more in 2012-2013 (Source: Venture Intelligence). E-tail market was getting popularities in Indian non metropolitan cities, 50\% of myntra.com (myntra.com) sales was from out side of 10 big cities of India, proved the popularity across India.

\section{What induced Indian users to shop online?}

Online Searching for needed products and services, comparing alternative options with respect to features and prices and actual purchasing, always had been influenced by a set of socio-cultural attributes or variables in Indian context. Following are the positive influencers which impacted Indian online purchasing decision and drove them for actual online searching and shopping:

Repetitive widespread advertisements of Indian E-tailing portals through television prime slots, print media, billboards, email catalogues and reviews posted in blogs, Facebook, tweets about already used online products and services generated attraction towards those portals. Positive word of mouth communications, feedback from existing users, and influences of peers, opinion leaders and mavens converted that attraction into strong purchase intentions from E-tailing sites. Attractive B2C websites with advanced user friendly interface technology, robust design, easy shopping cart, convenient payment gateway option, detailed product information with photographs and price tags, reliable and interesting web contents, easy customization facilities made searching easy for not so system and computer friendly Indians and this comfort level created trustworthiness towards the portals in the mind of Indian consumers who were by nature conservative and skeptical about online shopping. Being confident Indian online searchers then started participating in brand communities which in turn created a positive notion and trust for the available online brands. Indian consumers specially the women always feel deprived of feel and touch shopping experience while they went for online, which they would love to have. If the appeal of E-tailing sites included sensations, easy interaction options, thrills, emotional visuals and impromptu enjoyment, could overcome the previously mentioned problem in a great way. Arousing value for money feeling against an exchange, clearly understandable transaction processes and with integrated and synchronized online demand and supply would definitely strengthen online shopping model in India (saeed and Siti, 2012, journal-archievers\7.webs.com\297-311. pdf). Indian consumers are always value driven mass whether personal or social values, ecommerce sites which offered substantial values through their offerings were much more accepted by Indians.

Following were some general but strong reasons to push Indian users to buy online:

Feeling convenient while shopping online, Easy online navigation and interface facilities, Trustworthiness of ecommerce sites and brands, Relevant supply by online vendors against the exact demands of Indian online consumers, Relevant and detailed information about online products and services in portals, Time, money, cost and energy saving features of online shopping model, 24/7 anywhere - anytime shopping options for customers, this facility overcame the problem for E-tailers to reach wide geographically dispersed Indian consumers, Easy payment options like credit card, debit card, bank transfer and specially cash on delivery which was much more accepted and reliable options to Indian consumers who were conservative and skeptical about online data and payment securities, Diversified enough available online options, Comparative analysis options regarding product features and prices as Indians by nature were price sensitive and bargaining in nature, Positive feedbacks about already used products which were brought online, from opinion leaders called as mavens, made new online users confident to shop online, Influences of feedbacks and posting about online products from existing online users in social networking sites like Facebook, twitter, blogs etc. had greatly impacted the new online consumers online shopping decision process, Discounts and cheap deals offered by online vendors attracted many new online consumers greatly as Indians loved that, Quick, free or low cost at the door delivery and transparent return policies provided by the Indian online vendors encouraged Indian buyers for repetitive online shopping, Transparent privacy policies followed by online vendors with new secured payment option equipped with SSL technology, boosted Indian consumers to buy in the virtual world, Online shopping could be done through smart phones across India, Consistent service quality maintained by online vendors ensured online consumers retention in India and efficient, quick after sales service offered by online vendors made Indians happy and cemented the chance of next purchases from them.

\section{Hinderances for Indian Online Shoppers and E-Tailers}

Though India had $3^{\text {rd }}$ largest online users database in the world but the conversion rate regarding online shopping was still very low till 2014. It was found mainly women and rural users were either not interested or afraid of online buying. Following were some of the reasons or independent variables towards that negative online behavior in Indian context:

Feel and touch shopping experiences were absent, sometimes excess costs were incurred due to transaction costs. Privacy concerns of Indian online users, they were reluctant to expose personal details including credit and debit card details in virtual world. Concerns over durability 
and functionality of the available online products, Price sensitiveness of Indian consumers, Bad experiences over past online shopping, Technological complexities regarding online system usage, Penetration of internet including broadband across India was still very low, Logistic problems: wide geographical spread in India hindered online vendors to deliver on time, Problems of National and local online legalities and rules, Maximum online sellers did not clearly mention terms and conditions which stopped Indian users to buy online, Quite often it had been found that quality was different as claimed by the Indian online vendors and actually what consumers got, many Indian online vendors did not have dedicated 24/7 customer care centers, According to general Indian shopping behavior and psyche, people still preferred physical brick and mortar shopping model rather than online shopping model. Online shopping was devoid of human interactions which Indian consumers used to like, no chances of negotiations while doing online shopping, Indian consumers did not like that. Over choices in single product line confused Indian online users often, as Indians were conservative by nature so very few chances of impulse buying which was very effective with respect to online shopping. Non serious attitudes of Indian online vendors towards quick and efficient after sales services made online consumers dissatisfied. Charges for delivery, Indian online consumers often felt the problem of return of goods and refund of money thus breaking the trust on those portals and stopped Indians for repeat purchases. Lack of proper physical infrastructures which was needed for E-tailing in India. Unorganized business model followed by Indian E-retailers, Value added tax was another problem for E-tailers in India. Billing, dispatch and delivery fell under three different departments of Indian government, thus submission of taxes were very problematic for Indian vendors. Cyber crime was a big problem for E-tailing market in India. Non transparencies regarding payment gateways and securities, terrified Indian consumers' psyche. Well framed cyber laws were still missing, Many online E-commerce portals did not adopt SSL encryption technology to protect data, Mall cultures, where people got almost every brand under one roof which saved money, time and energy, were real time challenges for online shopping, Tele shopping like Tv18 network, Home Shopping network etc. were also proved challenges for Indian E-tailing market. Lack of local language driven contents in portals discouraged especially Indian rural online users. According to Indian consumers' psyche Indian online buyers liked cash on delivery model which many online vendors did not adopt, Product delivery systems in India was still very poor, only 1000 pin codes out of 1,00,000 were connected by courier services, thus creating problem for online vendors to deliver in time. Dealing with thousands of small suppliers rather than few large retailers, which was global online selling norm, created huge problem for Indian Online vendors. Mobile payment option was at very stage in India and so far was not very polar among Indian consumers especially rural ones, hindered the anytime - anywhere shopping process. Online social network sites which conveyed messages and postings about a used online product influenced greatly Indian Online buyers' psyche, but Indian existing consumers were not very keen to post in networking after usages, where global online Shoppers used to do that, Payment gateway errors irritated and stopped Indians to shop online. Too many Indian online vendors than needed created the situations like survival of the fittest thus encouraging them to opt for malpractices to sustain in the market, Managing Marketing Operating Price (MOP) by brands in the virtual world was big problem and was threat to Indian E-tailing market. Instead of original new products, portals were often found delivering old and damaged products at Indian consumers' premises thus damaging the consumers' notion of trust on the Indian online vendors and total E-tailing model.

\section{Recommendations for the betterment of future in the Indian E-Retail market and suggestions to overcome the challenges for online shopping in Indian context, Based on the findings in the study}

Online vendors should design such ecommerce portals which will offer more interactivity options, feelings, emotions and sense of enjoyments along with the detailed information about their offerings to gain popularity among Indian online users. Transparent business terms and conditions and special focus on privacy and data security, adopting advanced technologies will definitely increase the Indian online consumers trust on those portals. Durability and functionality of the online products should be checked before hand by the vendors before deliveries. Special offers and discounts will attract price sensitive Indians more too online shopping. Effective, quick after sales service will decrease the dissatisfaction of Indian consumers if they had already any bad experiences regarding online shopping and encourage them for repetitive purchases. Indian E-commerce portals should design simple without many technical complexities, user friendly portals with relevant and crisp product or service descriptions thus decreasing general conservative mental blockages of Indian online users with respect to computer and internet usages, In future Indian E-retail portals should include local language contents to attract Indian consumers specially the rural ones. All E-commerce portals should adopt cash on delivery option as price sensitive Indians will definitely prefer than other online payment options. More advanced infrastructures suitable for online shopping model should be provided by Indian government with more Internet penetration including the broadband across India. Cyber laws should be clearly and definitely mentioned to help online vendors to business in India and discouraging the cyber crimes which in turn will increase the trust among Indian online consumers. Online vendors should not go for many small suppliers, instead they should go for fewer big retailers and avoiding $3^{\text {rd }}$ party business model to give more maturity to Indian ecommerce market, Indian government should provide better physical infrastructures and road, water and air connectivity across the country to curb down the logistic problems for Indian online vendors who then can deliver products in time. Indian online vendors should focus on quality consistencies and deliver new and original products instead of old and damaged ones which will definitely encourage Indian consumers to buy next time. All Online portals should have dedicated 24/7 customer care centers to solve their existing consumers' problems instantly, Indian government and local bodies should lay down clear and flexible legal rules which will be helpful for the Indian online vendors to do business with ease. Online vendors should curb down the problem of over choices regarding their products and make easy for online buyers to choose from the limited ones, Minimum charges taken at the time of delivery on behalf of online vendors will definitely create the popularities of those vendors among Indian consumers. Sensitive return of goods and refund of money policies of online vendors will definitely generate trust among Indian consumers. More and more advertisements of online portals especially in non metro Indian cities and rural areas will attract more new Indian online users and retain existing customers. Existing Indian online consumers should post their valuable comments in ecommerce portals and social networking sites thus generating trust about the online products and portals, among new online users' mind. Online portals should bring down the payment gateway error instances with the help of the concerned Indian banks to create trust regarding online payments among conservative and price 
Citation: Ghosh D (2014) Why Indian E-Retailing Market is Still a Partly Success and a Partly Failure Story? J Account Mark 3: 113. doi: 10.4172/21689601.1000113

skeptical Indians. Indian online vendors should discourage coupon games instead of giving direct discounts, which in turn in long run will create false demand cycle which will be proved detrimental for Indian E-tailing market.

\section{Conclusion and Future Scope of the Study}

The main problem area of this research topic was to find why Indian online retailing market is still a partly success story, not achieving the desired goal. To find out the reasons the growth story of the E-commerce market in India since inception had been discussed along with the analysis of the behavioral pattern of Indian online shoppers. Main influencers behind the urge to shop online had been found during the research, this paper also investigated the main causes which hindered Indian users to shop online. Finally analyzing all the pros and cons a set of recommendations had been made in this paper to overcome the challenges for online shopping in Indian scenario to achieve the desired success in near future.

The present study may provide basis for future studies. This study paper may be proved as productive guidelines for online marketers to attract more new Indian online users toward online transactions. Future researchers may find few data from this paper useful for their research purposes.

\section{References}

1. Hoffman DL, Novak TP (1996) A New Marketing Paradigm for Electronic Commerce.

2. Singla BB, Kumar P, Kaur R (2012) Online Shopping: An innovative tool of Google success

3. IJMIE 2: 240-263.

4. http://www.indiatechonline.com, 2014.

5. http://www.internetlivestats.com, 2014.

6. Schiffman, Leon G, Kanuk, Lazar L (2004 ) Consumer Behaviour, Prentice Hall, NJ, USA.

7. Anderson C (2011) Indian e-commerce market growing despite payment challenges.

8. Amar S (2011) E-commerce in India: some real challenges.

9. Srikanth V, Umasilaja P (2007) Online purchasing Trends - Indian Scenario.

10. Challenges with ecommerce in India (2012)

11. Lina Z, Dai L, Zhang D (2007) Online shopping model - a critical survey of consumer factors in online shopping Journal Of Electronic Commerce Research 8: 1-42.

12. Dubey R (2012) Ecommerce poised for a leap in 2012.

13. eMarketer (2009) Internet users in India and ecommerce in India - a survey report.

14. Rastogi Ak (2010) A study of Indian Online consumers \& their buying behavior International Research Journal 1: 80-82.

15. Gupta S, Sayal H (2012) Emerging marketing approaches to influence customer behavior International Journal of Research in IT \& Management 2 Issue: 5, 2012. Link: mairec.orglIJRIMIMay2012।7.pdf

16. iXiGo.com (2010) Online travel buying behavior in India - a survey conducted by iXiGo.com", 2010. Link : dare.co.inlnewslotherslixigo.com-survey-revealsonline-travel-buying-behavior-in-india.html

17. Dholakia V(2010) How is online shopping evolving in India?

18. Leonard S (2011) A Journey of Exploration into the World of of E-Marketing and Independent Publishing.", Bud Werner Library, Steamboat Springs, CO .

19. Kumar R, Bakshi G (2012) A study of Indian online consumers and their buying behaviour IJRESS 2: 267-270.
20. Aggarwal S (2012) Why inventory -led e-commerce companies in India will not be profitable....Ever.

21. Singhi A, Shukla A (2012), "Retailing: Consumer purchase decision", Nationa Conference On Emerging Challenges For Sustainable Business, ISBN 978-93-81583-46-3 , 2012 . Link: domsittr.infolallpaperlRetailing Consumer Purchase_Decision_AkanshaSinghi_MKT040.pdf Accessed on : 26/11/2012

22. http://www.slideshare.net/iibea/digital-statistics-2014-india

23. Chitraparna (2011) Digital market growth opportunities in 2012 India: Consumer Behavior.

24. Kumar R, Khurana N (2012) Online shopping and identification of internet mavens in India IJRESS 2: 271-280.

25. Arora M, Yadav $V$ (2012) THE PRODUCT PURCHASE INTENTIONS IN FACEBOOK USING ANALYTICAL HIERARCHICAL PROCESS Radix International Educational and Research Consortium.

26. Sunitha G, Chandra SP (2012) E-tailing - The mantra of modern retailer's success International Refereed Research Journal.

27. Tripathy A (2012) What are the biggest challenges facing eCommerce sites in India?

28. Richa D (2012) IMPACT OF DEMOGRAPHIC FACTORS OF CONSUMERS ON ONLINE SHOPPING BEHAVIOUR : A STUDY OF CONSUMERS IN INDIA I.J.E.M.S. 3: 43-52.

29. Chanana N, Goele S (2012) FUTURE OF E-COMMERCE IN INDIA I.J.C.B.R

30. Bajpai A, Wen C, Lee (2014) Online buying behavior: A cross country study between India and Taiwan I.J.R.F.M. 4: 23-46.

31. Das S, Behura KC (2012) Future of online retailing in India VSRD-IJBMR 2 280-291.

32. Zhou L, Dai L, Zhang D (2007) Online shopping acceptance model - a critica survey of consumer factors in online shopping Journal Of Electronic Commerce Research 8: 41-61.

33. Potturi S, Sailaja U, Villivalam (2007) Ecommerce, online shopping and Internet marketing - analysis,trends and forecasts International Journal of Business Research.

34. Wang Y, Wu L, Chen $\mathrm{H}$, Yeh M (2012) The impact of interactivity on involvement and social presence: the moderating effects of opinion leadership. Pacific Asia Conference on Information Systems (PACIS), Korea.

35. Bansal M (2012) E-commerce in India - Present and future.

36. Behjati S, Othaman S (2012) WHAT DRIVES CONSUMERS' ONLINE SHOPPING? CONCEPTUAL REVIEW OF ONLINE SHOPPING ATTRIBUTES INVESTIGATED IN PREVIOUS STUDIES I.J.C.R.B. 3: 297-311.

37. Wigder Z, Bahl M, Wills K, Varon L (2012) Trends in India's eCommerce market For Ebusiness and Channel Strategy Professionals by Forrester Research.

38. Sharma S, Rehman A (2012) Assessing the impact of web 2.0 on consumer purchase decisions: Indian perspective IJMT 2: 125-138.

39. Chaharsoughi SA, Yasory TH (2011) Effect of sales promotion on consumer behavior based on Culture 6: 98-102.

40. Have Global E-tailers Missed the Bus in India?: India Knowledge@Wharton.

41. Khitoliya P (2014) e-Tailing - a Contemporaneous Dimension in E-Commerce IJSR 3: 74-77.

42. Kapoor D (2014) E-Tailing: A Case Study on Myntra.com IJAR 4 4:10-12.

43. Brynjolfsson E, Hu YJ, Rahman MS (2013) As technology blurs the distinctions between physical and online retailing, retailers and their supply-chain partners will need to rethink their competitive strategies. 